\title{
Postoperative prophylaxis in Crohn's disease after intestinal resection: a retrospective analysis
}

\author{
Anthony O'Connor, Peter J Hamlin, Jennifer Taylor, Christian Selinger, \\ Nigel Scott, Alexander C Ford
}

Leeds Gastroenterology Institute, St. James's University Hospital, Leeds, UK

\section{Correspondence to} Dr Anthony O'Connor, Leeds Gastroenterology Institute, Bexley Wing, St James's University Hospital, Leeds LS97TF, UK; jpoconno@tcd.ie

Received 31 August 2016 Revised 24 October 2016 Accepted 26 October 2016 Published Online First 1 December 2016
CrossMark

To cite: $O^{\prime}$ Connor $A$, Hamlin PJ, Taylor J, et al. Frontline Gastroenterology 2017; 8:203-209.

\begin{abstract}
Introduction Up to $80 \%$ of patients with Crohn's disease (CD) may require surgery at some point in their lives, and it is estimated that as many as $40 \%$ may require several surgeries. It has been suggested that prophylactic medication decreases the rate of clinical and endoscopic recurrence following intestinal resection. This study aims to describe real-world clinical outcomes observed from a pragmatic, individualised strategy in postoperative CD.
\end{abstract}

Methods All patients undergoing intestinal resection for CD between 2009 and 2013 were identified. The endpoint of the study, treatment success, was defined as glucocorticosteroid-free, resection-free survival, at the last point of followup, without requiring an escalation or change of therapy during this time. Clinical information was extracted from chart reviews, endoscopy and radiology reports, and from prescribing databases. Patients were followed from the date of surgery, and the last point of follow-up was 31 January 2015.

Results 149 patients were analysed. Median duration of follow-up was 32 months (range 1-69 months). 101 patients received postoperative prophylactic therapy, and 48 did not. In 77 (51.7\%) patients, thiopurines were used as first-line therapy, with treatment success occurring in $32(41.6 \%)$ with a median follow-up of 25 months. 11 patients (7.4\%) received antitumour necrosis factor (TNF)- $\alpha$ monotherapy, with treatment success occurring in 5 patients $(45.5 \%)$ with a median follow-up of 35 months. $13(8.7 \%)$ patients received first-line combination therapy, with 11 (84.6\%) patients achieving treatment success with a median follow-up of 21 months.

Conclusions In our study, combination therapy with anti-TNF- $\alpha$ and immunomodulator therapy was well tolerated, efficacious (efficacy appeared durable for patients with postoperative CD) and superior to monotherapy with either thiopurines or anti-TNF- $\alpha$ drugs. Several limitations notwithstanding, our data suggest that there may be merit in the use of combination therapy in carefully selected postoperative patients whose care has been individualised via a multidisciplinary team meeting format. Prospective, controlled studies are therefore required to further assess the efficacy and safety of combination therapy for postoperative prophylaxis in CD.

\section{INTRODUCTION}

Up to $80 \%$ of patients with Crohn's disease (CD) may require surgery at some point in their lives, and it is estimated that as many as $40 \%$ may require several surgeries. $^{1-4}$ Indications for surgery include failure of medical treatment, bowel obstruction, fistula or abscess formation. The most common surgical procedure is intestinal resection. Although in many cases, surgery may provide longterm disease control, the endoscopic recurrence rate is high. ${ }^{5-8}$ For patients who have undergone ileocaecal resection, which is the most common Crohn's resection, endoscopic recurrence rates are $73 \%$ and $85 \%$ at 1 and 3 years post surgery, respectively. ${ }^{2}$ The risk of clinical recurrence is estimated to be 20\%-25\% per year. ${ }^{9-11}$ It has been suggested that prophylactic medication decreases the rate of clinical and endoscopic recurrence following intestinal resection. The efficacy of several agents has been studied, including mesalazine, thiopurines, antitumour necrosis factor (TNF)- $\alpha$ drugs, such as infliximab and adalimumab, and 5-imidazole antibiotics, including metronidazole and ornidazole. ${ }^{12-17}$ However, the results of published studies have been 
inconsistent, and therefore, most gastroenterologists adopt a pragmatic approach, weighing the benefits of prophylaxis against the risks of adverse events from, and the costs of, therapy. ${ }^{18} \mathrm{~A}$ cost-effectiveness analysis reported that thiopurine drugs had the most favourable incremental cost-effectiveness ratio (ICER) in the prevention of clinical recurrence of postoperative $C D$ up to 1 year, and mesalazine the most favourable ICER at 5 years. ${ }^{19} 20$ Interestingly, in this study, anti-TNF- $\alpha$ agents, which have some of the most impressive data, in terms of their ability to reduce endoscopic recurrence, were the least cost-effective, with an ICER per quality-adjusted life year of $\$ 1.9$ million. For these, and other, reasons, published guidelines from major professional gastroenterological societies have been inconsistent in their recommendations concerning postoperative prophylaxis, and therefore adoption of a standardised practice in this situation has not occurred. The American College of Gastroenterology recommends that metronidazole, mesalazine, thiopurines or infliximab should be considered. ${ }^{21}$ The European Crohn's and Colitis Organisation recommends prophylactic treatment after small intestinal resection, and favours thiopurines over 5 -aminosalicylates or imidazole antibiotics, ${ }^{22}$ but the British Society of Gastroenterology does not endorse this view. ${ }^{23}$ This study aims to describe real-world clinical outcomes observed from a pragmatic, individualised strategy in postoperative CD.

\section{METHODS}

\section{Study population}

The study was conducted in Leeds Teaching Hospitals Trust, West Yorkshire, UK. The hospitals provide secondary care services to a local population of almost 800000 people in the North of England. All patients undergoing intestinal resection for $\mathrm{CD}$ between 1 January 2009 and 31 December 2013 were identified at our hospitals, by interrogation of the pathology database. Patients who usually had their CD cared for in an external centre, but who attended our institution for surgery as tertiary referrals, were excluded.

\section{Definitions}

The endpoint of the study, treatment success, was defined as glucocorticosteroid-free, resection-free survival, at the last point of follow-up, without requiring an escalation or change of therapy during this time. Primary loss of response was defined as a need for glucocorticosteroids, a further surgical resection or escalation or change of therapy within 1 year of commencing the initial postsurgical regimen, and secondary loss of response was defined as a need for glucocorticosteroids, a further surgical resection or escalation or change of therapy beyond 1 year. Intolerance was defined as the need to discontinue any therapy due to a drug-related adverse event.

\section{Data extraction}

Clinical information was extracted from chart reviews, endoscopy and radiology reports, and from prescribing databases. Patients were followed from the date of surgery, and the last point of follow-up was 31 January 2015.

\section{Statistical analysis}

Continuous variables were expressed as median and range (minimum and maximum). Categorical variables were compared using Fisher's exact test with Yates' correlation. A two-tailed $\mathrm{p}$ value of $<0.05$ was considered to indicate statistical significance. All analyses were performed using SPSS for Windows V.20 (SPSS, Chicago, Illinois, USA).

\section{RESULTS}

In total, 179 patients attended for a surgical resection over the study period. Twenty-seven of these patients were tertiary referrals, and had their CD cared for in an external centre, and three were participants in a drug trial. These individuals were therefore excluded, leaving 149 patients with complete data for analysis. The median duration of follow-up was 32 months (range 1-69 months). There were 101 patients who received postoperative prophylactic therapy and 48 who did not (figure 1). Baseline characteristics of all 149 subjects are provided in table 1 . With respect to the surgical procedure performed, $106(67.8 \%)$ patients had an ileocaecal resection or right hemicolectomy, 21 (14.1\%) patients had a small intestinal resection, 12 (8.1\%) had a subtotal colectomy, 6 (4.0\%) underwent panproctocolectomy and $4(2.7 \%)$ had a left hemicolectomy or sigmoid resection. Forty-eight (32.2\%) resections were unscheduled procedures for acute, or severe subacute, obstructive symptoms, with the remainder being scheduled elective procedures. There were $14(9.4 \%)$ patients who did not have a previous known diagnosis of $\mathrm{CD}$, and who were presenting for the first time for emergency surgery. Outcomes are summarised in table 2. Kaplan- Meier survival curves are provided in figure 2 .

\section{Thiopurine monotherapy}

In $77(51.7 \%)$ patients, thiopurines were used as firstline monotherapy. Treatment success occurred in 32 of these patients (41.6\%), after a median follow-up of 25 months (range 7-68 months). Intolerance to thiopurines occurred in 18 patients (23.4\%). There were 11 patients $(14.3 \%)$ who had a primary nonresponse, and $11(14.3 \%)$ had a secondary loss of response. A further four patients (5.2\%) were lost to follow-up before 1 year, and one patient died of sepsis related to nutritional failure. Median time to loss of response among the secondary loss of 


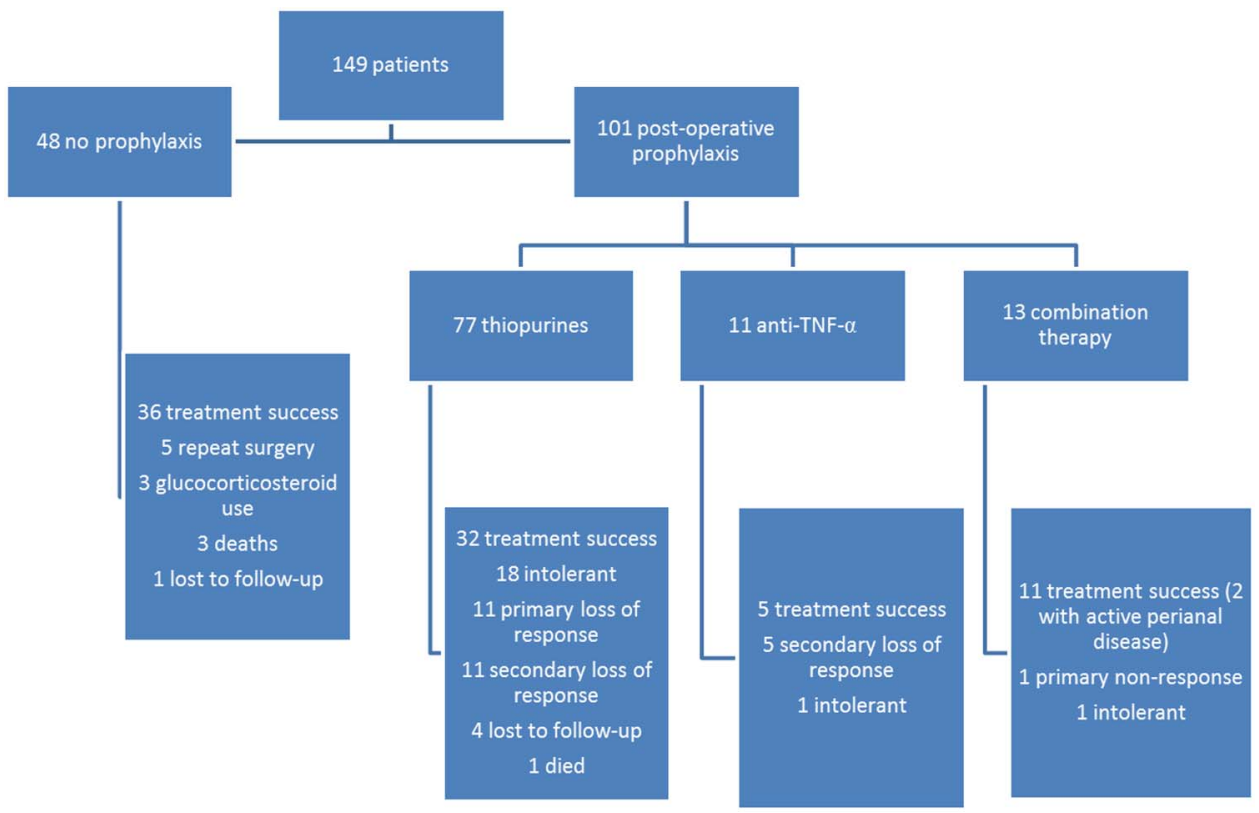

Figure 1 Patient flow chart.

Table 1 Baseline characteristics of study participants

\begin{tabular}{|c|c|c|c|c|c|c|}
\hline & $\begin{array}{l}\text { All patients } \\
(n=149)\end{array}$ & $\begin{array}{l}\text { Patients } \\
\text { receiving } \\
\text { prophylaxis } \\
(n=101)\end{array}$ & $\begin{array}{l}\text { Patients receiving } \\
\text { thiopurine } \\
\text { monotherapy } \\
(n=77)\end{array}$ & $\begin{array}{l}\text { Patients receiving } \\
\text { anti-TNF } \\
\text { monotherapy } \\
(\mathrm{n}=11)\end{array}$ & $\begin{array}{l}\text { Patients receiving } \\
\text { combination } \\
\text { therapy }(n=13)\end{array}$ & $\begin{array}{l}\text { No } \\
\text { prophylaxis } \\
(n=48)\end{array}$ \\
\hline \multicolumn{7}{|l|}{ Gender } \\
\hline Male & $61(40.9 \%)$ & $41(40.6 \%)$ & $33(42.9 \%)$ & $4(36.4 \%)$ & $6(46.2 \%)$ & $20(41.6 \%)$ \\
\hline Female & $88(59.1 \%)$ & $60(59.4 \%)$ & $44(57.1 \%)$ & $7(63.6 \%)$ & $7(53.8 \%)$ & $28(58.4 \%)$ \\
\hline \multicolumn{7}{|l|}{ Montreal age } \\
\hline A1 (below 16 years) & $30(20.1 \%)$ & $19(18.8 \%)$ & $13(16.9 \%)$ & $2(18.2 \%)$ & $4(30.8 \%)$ & $11(22.9 \%)$ \\
\hline A2 (17-40 years) & $91(61.1 \%)$ & $67(66.3 \%)$ & $54(70.1 \%)$ & $7(63.6 \%)$ & $6(46.2 \%)$ & $24(50.0 \%)$ \\
\hline A3 (over 40 years) & $28(18.8 \%)$ & $15(14.9 \%)$ & $10(13 \%)$ & $2(18.2 \%)$ & $3(23.1 \%)$ & $13(27.1 \%)$ \\
\hline \multicolumn{7}{|l|}{ Montreal location } \\
\hline L1 (ileal) & $27(18.1 \%)$ & $18(17.8 \%)$ & $14(18.2 \%)$ & $2(18.2 \%)$ & $2(15.4 \%)$ & $9(18.8 \%)$ \\
\hline L2 (colonic) & $19(12.8 \%)$ & $8(7.9 \%)$ & $5(6.5 \%)$ & $1(9.1 \%)$ & $2(15.4 \%)$ & $11(22.9 \%)$ \\
\hline L3 (ileocolonic) & $103(69.1 \%)$ & $75(74.3 \%)$ & $58(75.3 \%)$ & $8(72.8 \%)$ & $9(69.2 \%)$ & $28(58.3 \%)$ \\
\hline \multicolumn{7}{|l|}{ Montreal behaviour } \\
\hline $\begin{array}{l}\text { B1 (non-stricturing, } \\
\text { non-penetrating) }\end{array}$ & $19(12.8 \%)$ & $12(11.9 \%)$ & $9(11.7 \%)$ & $1(9.1 \%)$ & $2(15.4 \%)$ & $7(14.6 \%)$ \\
\hline B2 (stricturing) & $90(60.4 \%)$ & $101(58.4 \%)$ & $46(59.7 \%)$ & $5(45.5 \%)$ & $8(61.5)$ & $31(64.6 \%)$ \\
\hline B3 (penetrating) & $40(26.8 \%)$ & $30(29.7 \%)$ & $22(28.6 \%)$ & $5(45.5 \%)$ & $3(23.1 \%)$ & $10(20.9 \%)$ \\
\hline $\begin{array}{l}\text { Previous Crohn's } \\
\text { resection }\end{array}$ & $53(35.6 \%)$ & $36(35.6 \%)$ & $23(29.9 \%)$ & $6(54.5 \%)$ & $7(53.8)$ & $17(35.4 \%)$ \\
\hline $\begin{array}{l}\text { Smoking (at time of } \\
\text { surgery) }\end{array}$ & $46(30.9 \%)$ & $30(29.7 \%)$ & $24(31.2 \%)$ & $3(27.3 \%)$ & $3(23.1$ & $16(33.3 \%)$ \\
\hline \multicolumn{7}{|l|}{ Preoperative treatment } \\
\hline $\begin{array}{l}\text { No } \\
\text { immunomodulator }\end{array}$ & $53(34.9 \%)$ & $29(28.7 \%)$ & $29(37.7 \%)$ & 0 & $1(7.7 \%)$ & $24(50.0 \%)$ \\
\hline Thiopurine & $90(60.4 \%)$ & $66(65.3 \%)$ & $45(58.4 \%)$ & $10(90.9 \%)$ & $10(76.9 \%)$ & $24(50.0 \%)$ \\
\hline Methotrexate & $26(17.4 \%)$ & $18(17.8 \%)$ & $6(7.8 \%)$ & $5(45.5 \%)$ & $5(38.5 \%)$ & $8(16.7 \%)$ \\
\hline Anti-TNF- $\alpha$ & 49 (32.9\%) & $34(33.7 \%)$ & $18(23.4 \%)$ & $9(81.8 \%)$ & $7(53.8 \%)$ & 15 (31.3\%) \\
\hline
\end{tabular}

TNF, tumour necrosis factor. 


\begin{tabular}{llll}
\hline & \multicolumn{2}{l}{ Agent used as first-line therapy } & \\
\cline { 2 - 4 } & Thiopurines $(\mathrm{n}=77)$ & Anti-TNF- $\alpha(\mathrm{n}=11)$ & Combination therapy $(\mathrm{n}=13)$ \\
\hline Median interval between surgery and starting therapy & 15 weeks $(3-210)$ & 17 weeks $(4-35)$ & 12 weeks $(6-156)$ \\
Exposure to same treatment before surgery & $45(58.4 \%)$ & $9(81.8 \%)$ & $3(23.1 \%)$ \\
Intolerance & $18(23.4 \%)$ & $1(9.1 \%)$ & $1(7.7 \%)$ \\
Treatment success & $32(41.6 \%)$ & $5(45.5 \%)$ & $0(0 \%)$ \\
Death & $1(1.3 \%)$ & $0(0 \%)$ & $1(7.7 \%)$ \\
Non-response & $11(14.3 \%)$ & $0(0 \%)$ & $2(15 \%)^{*}$ \\
$1^{\circ}$ & $11(14.3 \%)$ & $5(45.5 \%)$ & $0(0 \%)$ \\
$2^{\circ}$ & $3(3.9 \%)$ & $0(0 \%)$ & $1(7.7 \%)$ \\
Required second resection before end of follow-up & $20(26 \%)$ & $3(27.3 \%)$ & $0(0 \%)$ \\
Required glucocorticosteroids & $4(5.2 \%)$ & $0(0 \%)$ & \\
Lost to follow-up & &
\end{tabular}

*Two patients progressed with perianal disease on treatment, although remaining in remission luminally.

TNF, tumour necrosis factor.

response group was 22 months (range 16-76 months) (table 2).

\section{Anti-TNF-a monotherapy}

A total of 11 patients (7.4\%) received anti-TNF- $\alpha$ monotherapy as first-line treatment postoperatively. Treatment success occurred in five patients (45.5\%), with a median follow-up among these individuals of 35 months (11-50 months). Intolerance to anti-TNF- $\alpha$ occurred in only one patient $(9.1 \%)$. The remaining five patients $(45.5 \%)$ experienced a secondary loss of response. Median duration to loss of response among this group was 22 months (range 17-29 months) (table 2). The $\mathrm{p}$ value for anti-TNF- $\alpha$ monotherapy versus thiopurines was 0.8615 .

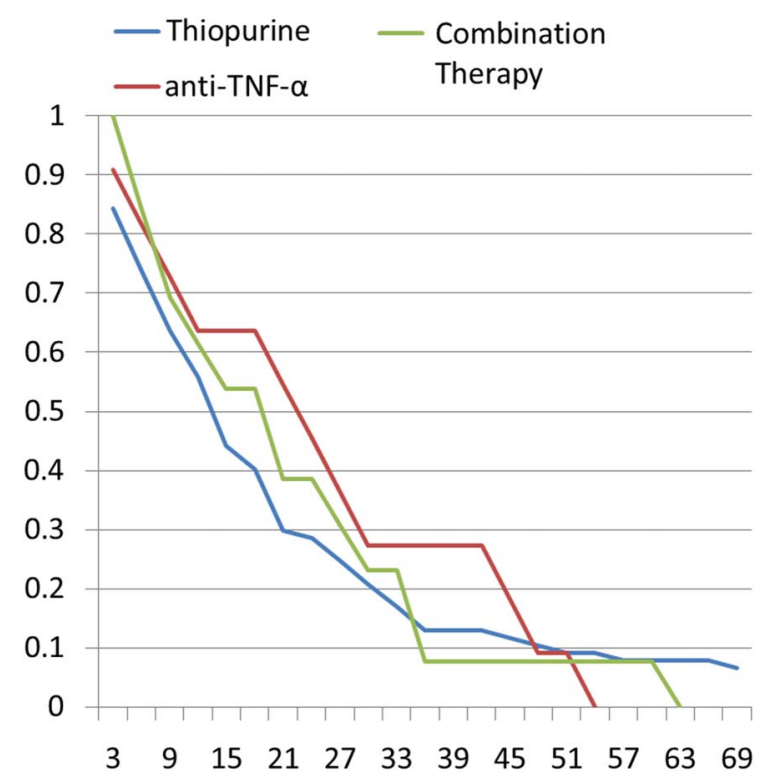

Figure 2 Kaplan-Meier curves for steroid-free, resection-free survival on various postoperative prophylactic therapies. TNF, tumour necrosis factor.

\section{Combination therapy}

In total, $13(8.7 \%)$ patients received first-line combination therapy with an anti-TNF- $\alpha$ agent and an immunomodulator postoperatively. The most frequently used combination was infliximab with azathioprine $(n=5)$, followed by adalimumab with azathioprine $(n=3)$, adalimumab with methotrexate $(n=3)$ and adalimumab with mercaptopurine $(n=2)$. Eleven $(84.6 \%)$ patients achieved treatment success at study end, with a median follow-up for responders of 21 months. However, two of these had experienced disease progression, with new perianal disease. For the purposes of this study, although strictly meeting our endpoint, these patients are classed as having a secondary loss of response in table 2. Of the remaining two patients, one (7.7\%) had a primary non-response, and the other was intolerant of combination therapy with a marked derangement in liver enzymes, and subsequently required further surgery. There were no patients who experienced a secondary loss of response with respect to luminal disease (table 2). The $p$ values for combination therapy versus anti-TNF- $\alpha$ monotherapy and thiopurines were 0.1111 and 0.0127 , respectively.

\section{No treatment}

Forty-eight patients received no prophylactic treatment between the date of surgery and the end of follow-up. Of these, 36 (75.0\%) met the criteria for treatment success at the end of follow-up. Five $(10.4 \%)$ patients required further surgery, three $(6.3 \%)$ patients required glucocorticosteroids and one (2.1\%) patient was lost to follow-up. Three (6.3\%) patients who did not have prophylaxis died (one from nutritional failure, one from sepsis and in one patient the cause was unknown). Median duration of follow-up among this group was 30 months (range 968 months). Median duration to loss of response in this group was 20 months (range 4-32 months). 


\section{DISCUSSION}

The goal of therapy for postoperative prophylaxis is to decrease clinical and endoscopic recurrence. Not all patients will develop clinical recurrence, and so treating everyone may not be either cost-effective or desirable, due to the potential adverse effects of thiopurines or anti-TNF- $\alpha .{ }^{18}$ Each patient requires an individual risk assessment as well as careful consideration as to prior therapies received and what led them to surgery. ${ }^{24}$ In our study, the outcomes seemed favourable for patients who received no treatment, but it must be borne in mind that this was a selfselecting cohort of patients under review by an IBD multidisciplinary team (MDT), in whom treatment was not felt to be indicated. It may be also notable that this group was more likely to have been older when diagnosed with $\mathrm{CD}$, and to have pure colonic disease. The death rate in this cohort was higher, and the patient who died of nutritional failure had refused all $C D$ treatments. In addition, over the course of follow-up for this retrospective study, many of the referenced papers were published, and key opinion leaders and consensus guidelines were emerging to address the issue. Many of these were divergent, and this diversity was reflected in the discussions of our MDT group, which explains some of the inconsistency of practice over that time.

There can be significant difficulties in the UK in accessing anti-TNF therapy for postoperative patients, and under the relevant National Institute for Health and Care Excellence, a requirement is in place to illustrate objective evidence of disease in order to justify use of the drug. This constraint informed many of the decisions of the group.

The outcomes for use of thiopurine monotherapy for postoperative prophylaxis in our cohort are disappointing, with low rates of treatment success at the end of follow-up and a high level of intolerance. In most cases of intolerance, switching to an alternative thiopurine was also a futile act. However, in many patients, thiopurines were started empirically without symptoms or evidence of disease recurrence. In those who tolerated the drug, primary loss of response, as defined by failure to reach our endpoint by 1 year, was relatively low, and median duration to loss of response in this group was 2 years. Although the use of thiopurines as postoperative prophylaxis is widespread, their efficacy in this setting has only been examined in three placebo-controlled trials. In two studies, a reduction in the rate of endoscopic recurrence was noted in the thiopurine arm at 1 year, ${ }^{25} 26$ although one of these studies involved the concurrent use of metronidazole. ${ }^{26}$ In a meta-analysis that pooled these data, thiopurines led to a $41 \%$ reduction in the risk of clinical recurrence and a 36\% reduction in the risk of endoscopic recurrence. ${ }^{27}$ By contrast, in the large UK-based TOPPIC trial, mercaptopurine led to a modest reduction in the frequency of clinical recurrence of $\mathrm{CD}$ postoperatively among smokers, but not non-smokers. ${ }^{28}$

Anti-TNF- $\alpha$ monotherapy has been shown in a number of prospective studies of mixed methodology to have benefits compared with placebo, mesalazine and thiopurines. ${ }^{29-32}$ Small randomised studies have also shown infliximab to be effective at preventing endoscopic and histological recurrence of $\mathrm{CD}$ at 1 and 5 years, although these studies were underpowered to detect meaningful differences in clinical recurrence. $^{12} 162033$ Outcomes in the group receiving anti-TNF- $\alpha$ monotherapy as a first-line treatment in our cohort were similar to those observed with thiopurine therapy, with $46 \%$ and $40 \%$, respectively, achieving treatment success. When used, timing of introduction of anti-TNF- $\alpha$ monotherapy was similar to thiopurine monotherapy, and, in most cases, it was commenced empirically for prophylaxis without symptoms or objective evidence of disease recurrence. Ten of the eleven patients remained asymptomatic, with no recurrence within 1 year, and the remaining patient was intolerant. However, response was lost subsequently in half of these cases during median follow-up of 32 months. This is congruent with published data on the annual risk of loss of response to infliximab monotherapy in $\mathrm{CD}$, which is estimated to be in the region of $13 \% .^{34}$

Data on the use of combination therapy postoperatively are sparse. One small non-randomised study of combination therapy with infliximab and methotrexate reported that no patients had endoscopic or clinical recurrence during 2 years of follow-up, compared with 12 of 16 patients with a recurrence in a comparator group of patients who received mesalazine alone. ${ }^{35}$ In our study, combination therapy with anti-TNF- $\alpha$ and immunomodulator therapy was well tolerated, efficacious (efficacy appeared durable for patients with postoperative $\mathrm{CD}$ ) and superior to monotherapy with either thiopurines or anti-TNF- $\alpha$ drugs. Most patients in this small cohort had had more than one Crohn's resection and were exposed to monotherapy with thiopurines and anti-TNF prior to surgery, and it is encouraging that there may be some role for combination therapy in these difficult, refractory patients.

There are several limitations to our study. It is a single-centre retrospective analysis. It is likely that decisions made on when to introduce anti-TNF- $\alpha$ drugs and combination therapy would have been made at an expert MDT meeting, whereas the majority of patients commencing azathioprine would have just resumed it routinely postoperatively, or been started on it by individual clinicians or fellows in the setting of an outpatient clinic. There is therefore the potential bias that those receiving anti-TNF- $\alpha$ drugs and combination therapy were experiencing a more sophisticated level of care, having had high-level MDT discussion, and that this could explain their better outcomes. In addition, in most of the patients 
who received combination therapy postoperatively, this was a genuine escalation of treatment, with very few having prior exposure to combination therapy.

These limitations notwithstanding, our data suggest that there may be merit in the use of combination therapy in carefully selected postoperative patients whose care has been individualised via an MDT meeting format. Combination therapy has become accepted as the optimum disease-modifying regimen for patients with severe inflammatory bowel disease. ${ }^{36}$ More recent data have pointed towards a reduced risk of major adverse events including occurrence of surgery, hospital admission or serious disease-related complications in centres that use early combined immunotherapy compared with those that adopt a more conventional 'step-up' management approach. ${ }^{37}$ In addition, our data suggest that there is a sizeable cohort of patients who manage well without prophylactic therapy, and that an IBD MDT meeting is well placed to identify these. Given that prior surgery in CD is a prognosticator for future disease progression and a complicated disease course, it is intuitive that high-risk patients may be among those who would derive the greatest benefit from the most efficacious treatment. However, any possible benefit needs to be weighed against the potential complications of combination therapy, including increased risk of infection and also of lymphoma in young males and older patients. ${ }^{38-40}$ Prospective, controlled studies are therefore required to further assess the efficacy and safety of combination therapy for postoperative prophylaxis in $\mathrm{CD}$.

\section{Significance of this study}

\section{What is already known on this topic?}

Up to $80 \%$ of patients with Crohn's disease (CD) may require surgery at some point in their lives, and it is estimated that as many as $40 \%$ may require several surgeries. Thiopurines and anti-tumour necrosis factor (TNF) agents have been shown in some randomised studies to reduce endoscopic and clinical recurrence, but results have been mixed and consensus guidelines vary.

\section{What this study adds?}

This is a retrospective experiential study from a large inflammatory bowel disease (IBD) centre. Thiopurines were poorly tolerated and of limited efficacy. Anti-TNF monotherapy was better tolerated, but of similar efficacy. In a small selected subgroup identified in a multidisciplinary team setting, combination therapy was well tolerated and efficacious, particularly in those who had had more than one resection.

\section{How might it impact on clinical practice in the foreseeable future?}

More studies are required on the role of combination therapy in postoperative patients.
Twitter Follow Anthony O'Connor at @antcon7062

Contributors AO and ACF: project conception, data collection and synthesis, statistical analysis, drafting of manuscript. PJH and CS: project conception, data synthesis, drafting of manuscript. JT and NS: data collection.

Competing interests $\mathrm{AO}$ received a travelling fellowship grant from MSD Human Health Ireland in 2013.

Provenance and peer review Not commissioned; externally peer reviewed.

\section{REFERENCES}

1 Bernell O, Lapidus A, Hellers G. Risk factors for surgery and recurrence in 907 patients with primary ileocaecal Crohn's disease. Br J Surg 2000;87:1697-701.

2 Rutgeerts P, Geboes K, Vantrappen G, et al. Predictability of the postoperative course of Crohn's disease. Gastroenterology 1990;99:956-63.

3 Cosnes J, Nion-Larmurier I, Beaugerie L, et al. Impact of the increasing use of immunosuppressants in Crohn's disease on the need for intestinal surgery. Gut 2005;54:237-41.

4 Vermeire S, van Assche G, Rutgeerts P. Review article: altering the natural history of Crohn's disease-evidence for and against current therapies. Aliment Pharmacol Ther 2007;25:3-12.

5 Kim NK, Senagore AJ, Luchtefeld MA, et al. Long-term outcome after ileocecal resection for Crohn's disease. Am J Surg 1997;63:627-33.

6 Nordgren SR, Fasth SB, Oresland TO, et al. Long-term follow-up in Crohn's disease. Mortality, morbidity, and functional status. Scand J Gastroenterol 1994;29:1122-8.

7 Ryan WR, Allan RN, Yamamoto T, et al. Crohn's disease patients who quit smoking have a reduced risk of reoperation for recurrence. Am J Surg 2004;187:219-25.

8 Fazio VW, Marchetti F. Recurrent Crohn's disease and resection margins: bigger is not better. Adv Surg 1999;32:135-68.

9 Becker JM. Surgical therapy for ulcerative colitis and Crohn's disease. Gastroenterol Clin North Am 1999;28:371-90.

10 Onali S, Petruzziello C, Calabrese E, et al. Frequency, pattern, and risk factors of postoperative recurrence of Crohn's disease after resection different from ileocolonic. J Gastrointest Surg 2009;13:246-52.

11 Sachar DB, Lemmer E, Ibrahim C, et al. Recurrence patterns after first resection for stricturing or penetrating Crohn's disease. Inflamm Bowel Dis 2009;15:1071-5.

12 Regueiro M, Kip KE, Baidoo L, et al. Postoperative therapy with infliximab prevents long-term Crohn's disease recurrence. Clin Gastroenterol Hepatol 2014;12:1494-502.

13 Regueiro M, Feagan BG, Zou B, et al. Infliximab reduces endoscopic, but not clinical, recurrence of Crohn's disease after ileocolonic resection. Gastroenterology 2016;150:1568-78.

14 De Cruz P, Kamm MA, Hamilton AL, et al. Efficacy of thiopurines and adalimumab in preventing Crohn's disease recurrence in high-risk patients-a POCER study analysis. Aliment Pharmacol Ther 2015;42:867-79.

15 Rutgeerts P, Van Assche G, Vermeire S, et al. Ornidazole for prophylaxis of postoperative Crohn's disease recurrence: a randomized, double-blind, placebocontrolled trial. Gastroenterology 2005;128:856-61.

16 De Cruz P, Kamm MA, Hamilton AL, et al. Crohn's disease management after intestinal resection: a randomised trial. Lancet 2015;385:1406-17. 
17 Ford AC, Khan KJ, Talley NJ, et al. 5 -aminosalicylates prevent relapse of Crohn's disease after surgically induced remission: systematic review and metaanalysis. Am J Gastroenterol 2011;106:413-20.

18 Vaughn BP, Moss AC. Prevention of post-operative recurrence of Crohn's disease. World J Gastroenterol 2014; 20:1147-54.

19 Doherty GA, Miksad RA, Cheifetz AS, et al. Comparative cost-effectiveness of strategies to prevent postoperative clinical recurrence of Crohn's disease. Inflamm Bowel Dis 2012;18:1608-16.

20 Savarino E, Bodini G, Dulbecco P, et al. Adalimumab is more effective than azathioprine and mesalamine at preventing postoperative recurrence of Crohn's disease: a randomized controlled trial. Am J Gastroenterol 2013;108:1731-42.

21 Lichtenstein GR, Hanauer SB, Sandborn WJ. Management of Crohn's disease in adults. Am J Gastroenterol 2009;104:465-83.

22 Van Assche G, Dignass A, Reinisch W, et al. The second European evidence-based Consensus on the diagnosis and management of Crohn's disease: Special situations. J Crohns Colitis 2010;4:63-101.

23 Mowat C, Cole A, Windsor A, et al. Guidelines for the management of inflammatory bowel disease in adults. Gut 2011;60:571-607.

24 Moss AC. Prevention of postoperative recurrence of Crohn's disease: what does the evidence support? Inflamm Bowel Dis 2013; 19:856-9.

25 Hanauer SB, Korelitz BI, Rutgeerts P, et al. Postoperative maintenance of Crohn's disease remission with 6-mercaptopurine, mesalamine, or placebo: a 2-year trial. Gastroenterology 2004;127:723-9.

26 D'Haens GR, Vermeire S, Van Assche G, et al. Therapy of metronidazole with azathioprine to prevent postoperative recurrence of Crohn's disease: a controlled randomized trial. Gastroenterology 2008;135:1123-1129.

27 Doherty G, Bennett G, Patil S, et al. Interventions for prevention of post-operative recurrence of Crohn's disease. Cochrane Database Syst Rev 2009;(4):CD006873.

28 Arnott I, Mowat C, Ennis H, et al. The TOPPIC Trial: a randomised, double-blind parallel-group trial of mercaptopurine versus placebo to prevent recurrence of Crohn's disease following surgical resection in 240 patients DOI: S21-S22 First published online: 7 March 2016.
29 Yamamoto T, Umegae S, Matsumoto K. Impact of infliximab therapy after early endoscopic recurrence following ileocolonic resection of Crohn's disease: a prospective pilot study. Inflamm Bowel Dis 2009;15:1460-6.

30 Araki T, Uchida K, Okita Y, et al. Impact of postoperative infliximab maintenance therapy on preventing the surgical recurrence of Crohn's disease: a single-center paired case-control study. Surg Today 2014;44:291-6.

31 Sorrentino D, Paviotti A, Terrosu G, et al. Low-dose maintenance therapy with infliximab prevents postsurgical recurrence of Crohn's disease. Clin Gastroenterol Hepatol 2010;8:591-9.

32 Sorrentino D, Terrosu G, Paviotti A, et al. Early diagnosis and treatment of postoperative endoscopic recurrence of Crohn's disease: partial benefit by infliximab—a pilot study. Dig Dis Sci 2012;57:1341-8.

33 Regueiro M, Schraut W, Baidoo L, et al. Infliximab prevents Crohn's disease recurrence after ileal resection. Gastroenterology 2009;136:441-50.

34 Gisbert JP, Panés J. Loss of response and requirement of infliximab dose intensification in Crohn's disease: a review. Am J Gastroenterol 2009;104:760-7.

35 Sorrentino D, Terrosu G, Avellini C, et al. Infliximab with low-dose methotrexate for prevention of postsurgical recurrence of ileocolonic Crohn disease. Arch Intern Med 2007;167:1804.

36 Colombel JF, Sandborn WJ, Reinisch W, et al. Infliximab, azathioprine, or combination therapy for Crohn's disease. N Engl J Med 2010;362:1383.

37 Khanna R, Bressler B, Levesque BG, et al. Early combined immunosuppression for the management of Crohn's disease (REACT): a cluster randomised controlled trial. Lancet 2015;386:1825-34.

38 Kotlyar DS, Osterman MT, Diamond RH, et al. A systematic review of factors that contribute to hepatosplenic T-cell lymphoma in patients with inflammatory bowel disease. Clin Gastroenterol Hepatol 2011;9:36.

39 Beaugerie L, Brousse N, Bouvier AM, et al. Lymphoproliferative disorders in patients receiving thiopurines for inflammatory bowel disease: a prospective observational cohort study. Lancet 2009;374:1617.

40 Osterman MT, Haynes K, Delzell E, et al. Effectiveness and Safety of Immunomodulators With AntiTumor Necrosis Factor. Clin Gastroenterol Hepatol 2015;13:1293-1301. 